\title{
Retrospective Analysis of Esophageal Foreign Body Ingestion: Differences Among Weekday, Weekends, and Holidays
}

\author{
Lili Wu' \\ Guiyu Lei' \\ Ying Liu ${ }^{2}$ \\ Zheng Wei' \\ Yue Yin' \\ Yanru $\mathrm{Li}^{3}$ \\ Guyan Wang' \\ 'Department of Anesthesiology, Beijing \\ Tongren Hospital, Capital Medical \\ University, Beijing, People's Republic of \\ China; ${ }^{2}$ Operating Room, Beijing Tongren \\ Hospital, Capital Medical University, \\ Beijing, People's Republic of China; \\ ${ }^{3}$ Department of Otolaryngology Head \\ and Neck Surgery, Beijing Tongren \\ Hospital, Capital Medical University, Key \\ Laboratory of Otolaryngology, Head and \\ Neck Surgery (Ministry of Education of \\ China), Beijing, People's Republic of \\ China
}

Correspondence: Guyan Wang Department of Anesthesiology, Beijng Tongren Hospital, Capital Medical University, Beijing, People's Republic of China

Tel +8613910985139

Email guyanwang2006@I63.com
Purpose: Current data on the occurrence of EFBs in relation to different time periods are scant. The purpose of this study was to compare the occurrence, type and location of EFBs in people who presented at our center on weekdays, weekends and holidays.

Patients and Methods: A retrospective analysis of patients $(\mathrm{n}=1353)$ received rigid esophagoscopy for foreign body extraction under general anesthesia from January 2018 to 2020 December.

Results: The occurrence of EFB ingestion was significantly higher $(\mathrm{p}<0.05)$ on holidays (2.75/day) than on weekdays (0.91/day) and weekends (1.46/day). Patients were much older on holidays, with a mean age of $58.18 \pm 17.34$ years, than patients on weekdays $(54.71 \pm$ 16.71 years $)$ and weekends $(55.05 \pm 17.36$ years $)$.

Conclusion: Our findings demonstrate that EFB ingestion is most likely to occur on weekends and holidays, and elderly patients should be advised to chewing slowly and eating non-nuclear jujube, especially during holidays, to minimize their risk.

Keywords: esophageal foreign body, weekday, weekend, holiday

\section{Introduction}

Esophageal foreign body (EFB) ingestion has become a relatively common clinical problem, estimated at 13 cases per 100,000 people ${ }^{1,2}$ and accounting for approximately 1500 deaths in the USA annually. ${ }^{3}$ EFBs represent a major challenge for general surgeons, cardiothoracic surgeons, otolaryngologists, anesthesiologists, emergency department physicians, pediatricians and radiologists. The majority of ingested EFBs are benign courses that will naturally pass spontaneously through the gastrointestinal tract without harm; however, up to $20 \%$ of the patients require intervention, and approximately $1 \%$ of patients require surgery. ${ }^{4}$ Rigid esophagoscopy under general anesthesia has traditionally been used by otolaryngologists as the first-line treatment. ${ }^{5}$

Underlying esophageal pathology was part causes of foreign bodies obstruction and food bolus impaction. ${ }^{6-8}$ Eosinophilic esophagitis was identified in $27-35 \%$ of patients aged $<50$ years who ingested EFBs, and eosinophilic esophagitis has been increasingly recognized as a potential cause of EFB ingestion. ${ }^{9,10}$ Among patients without a structural etiology, several underlying factors have been reported, and seasonal variation was reported in one study in which the incidence rates of ingestion of EFBs in summer and fall were much higher than those in winter and 
spring; this may have be due to a coexisting atopic diathesis. ${ }^{11}$ Higher incidences of EFB ingestions were also observed during national athletic events, during which dietary indiscretions such as excess alcohol ingestion or overeating, often existed. ${ }^{12}$ Dietary customs are part of cultural identity and vary based on culture, religious beliefs, countries, and dates. As the saying goes, "bread is the staff of life", and eating a hearty dinner is a popular form of celebration in Chinese culture, which may affect the occurrence of EFBs.

Current data on the occurrence of EFBs in relation to different time periods are scant. The purpose of this study was to compare the occurrence, type and location of EFBs in people who presented at our center on weekday, weekends and holidays. We hypothesized that specific time periods were associated with dietary indiscretions, leading to increased rates of EFB ingestion.

\section{Patients and Methods Study Population Selection}

This retrospective observational study was approved by the Ethics Committee of Beijing Tongren Hospital, Capital Medical University in Beijing, China. This study was conducted in accordance with the Declaration of Helsinki and all study subjects provided written informed consent. In total, the data of 1353 consecutive patients who underwent foreign body extraction between January 2018 and December 2020 were collected from the electronic medical records database. All of the patients underwent emergency surgery with a rigid esophagoscope under general endotracheal anesthesia in the operating room. We set the age restriction at 18 years and older to reduce admission incidence bias and improve homogeneity to a certain extent because most of patients in our center were adult. All patients received otolaryngological local examinations, neck and chest radiographs (including anteroposterior and lateral views), and computed tomography (CT) scans of the neck and chest to assess the presence, location, size, configuration, and number of ingested objects. A flow diagram of the strategy for inclusion in this study is shown in Figure 1, and some typical images are presented in Figure 2. Figure 3. Cases were excluded if no foreign body was found during surgery or cases integral data were missing. Finally 1353 patients were enrolled in this study.

\section{Definitions, Data Collection}

An EFB was defined as a foreign body or food that was swallowed into the esophagus accidentally or deliberately and failed to pass naturally or with induced vomited, requiring surgery or endoscopy. Esophageal perforation was defined as penetration through the wall of the esophagus.

Patient data, included age, sex, and date of surgery, (date was divided into weekday, weekend and holiday depending on the statutory holidays in China), type of foreign body (including fish bone, jujube pit, chicken and duck bone, denture, plastic or metal item, shellfish or crab shell, and food bolus); and site of the foreign body (including upper esophagus, defined as within $22 \mathrm{~cm}$ of the upper incisor teeth, mid-esophagus defined as $22-30 \mathrm{~cm}$ from the upper incisor teeth, and lower esophagus, defined as the terminus of the mid-esophagus $(30 \mathrm{~cm})$ to the esophagogastric junction, the four narrowing site: 1) behind the cricoid cartilage at the cricopharyngeus muscle, 2) at the point the esophagus crosses in front of the aortic arch,3) at the level of the left main bronchus, and 4) at the point the esophagus passes through the diaphragm). Complications after foreign body extraction, including perforation and infection, were analyzed.

\section{Data Analysis}

Means and standard deviations (SDs) were calculated for normally distributed quantitative variables. Medians and interquartile ranges (IQRs) were calculated for quantitative variables with a skewed distribution. Quantitative variables were analyzed using Student's $t$ test or Wilcoxon rank-sum test when appropriate. Categorical variables were analyzed using percentages and analyzed using the Pearson chi-square test or Fisher's exact test when appropriate. A $p$ value less than 0.05 denoted statistical significance. All statistical analyses were carried out with the software package R v.3.4.0.

\section{Results}

Over a period of 3 years, including 581 weekdays, 393 weekends and 91 holidays, 1353 patients (530 patients on weekdays, 573 patients on weekends and 250 on holidays) underwent emergent esophageal foreign body extraction with rigid esophagoscopy. Table 1 shows characteristics and outcomes of patients in weekdays, weekends and holidays. The occurrence of EFB ingestion was significantly higher during the holidays (2.75/day) than 


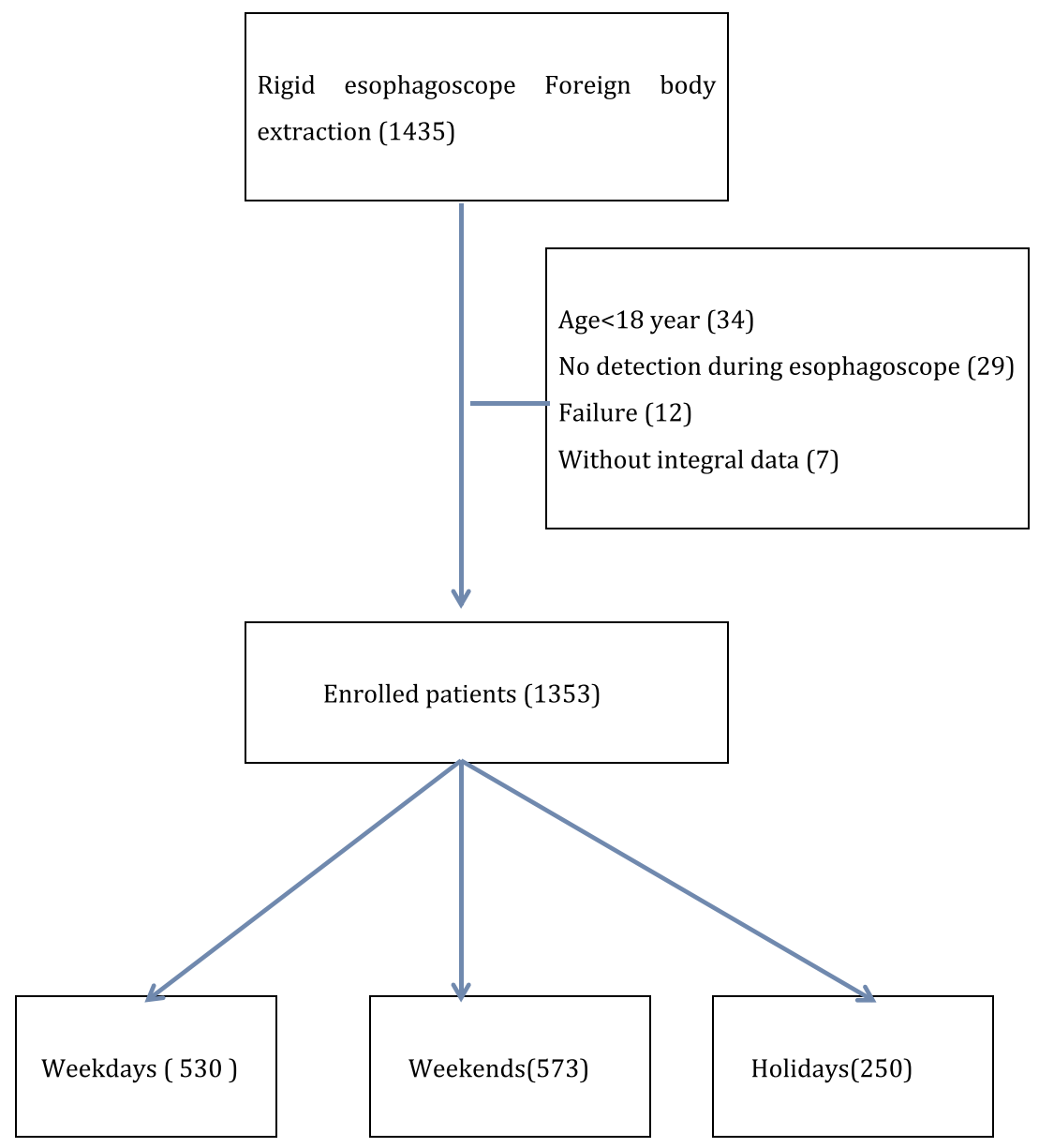

Figure I Flow chart of the overall study population. A retrospective study was conducted on adult patients who underwent EFBs extraction under general anesthesia in Beijing Tongren Hospital from January 2018 to January 2021. A total of 1353 patients who met the criteria were enrolled in the study.

on weekdays (0.91/day) and weekends (1.46/day), as shown in Figure 4. Of these patients, 496 (36.66\%) were male, and 857 (63.34\%) were female. The average age of whole people was $55.57 \pm 17.15$ years. Patients treated on holidays were much older, with a mean age of $58.18 \pm 17.34$ years, than patients treated on weekdays $(54.71 \pm 16.71$ years $)$ and weekends $(55.05 \pm 17.36$ years). Among the patients who were older than 55 years, the mean age was $67.20 \pm 9.53$ years for patients on weekdays, $68.69 \pm 9.74$ years for patients on weekends, and $69.56 \pm 9.27$ years for patients on holidays. And the occurrence of EFB during holidays was more than four times during weekdays, as shown in Figure 5. The age distributions were significantly different among the three groups $(\mathrm{p}=0.021)$. Among the three periods, the percentage of females was higher than that of males $(61.51 \%$ vs $38.49 \%, 62.65 \%$ vs $37.35 \%$, and $68.8 \%$ vs $31.2 \%$, respectively,), but no statistical difference was detected between the three periods.
The types of the foreign body were similarly distributes between the three periods $(\mathrm{p}=0.537)$. Jujube pit were the most common foreign bodies $(44.15 \%$ on weekdays, $43.28 \%$ on weekends, and $42.4 \%$ on holidays), followed by fish bones (30.94\% on weekdays, $30.19 \%$ on weekends, and $30.4 \%$ on holidays) and chicken and duck bones (14.72\% on weekdays, $17.8 \%$ on weekends, and $19.6 \%$ on holidays). The proportions of denture prosthesis and food bolus ingestion were relatively low.

The locations of foreign bodies were not significantly different among weekdays, weekends and holidays $(\mathrm{p}=0.465)$. Most foreign bodies were located in the upper esophagus ( $73.58 \%, 73.12 \%$ and $72.0 \%$, respectively,). The proportions of serious complications, including perforation and infection, were similar among the three groups.

\section{Discussion}

EFB ingestion is a common cause of emergency department visits, estimated at more than 1000,000 cases 


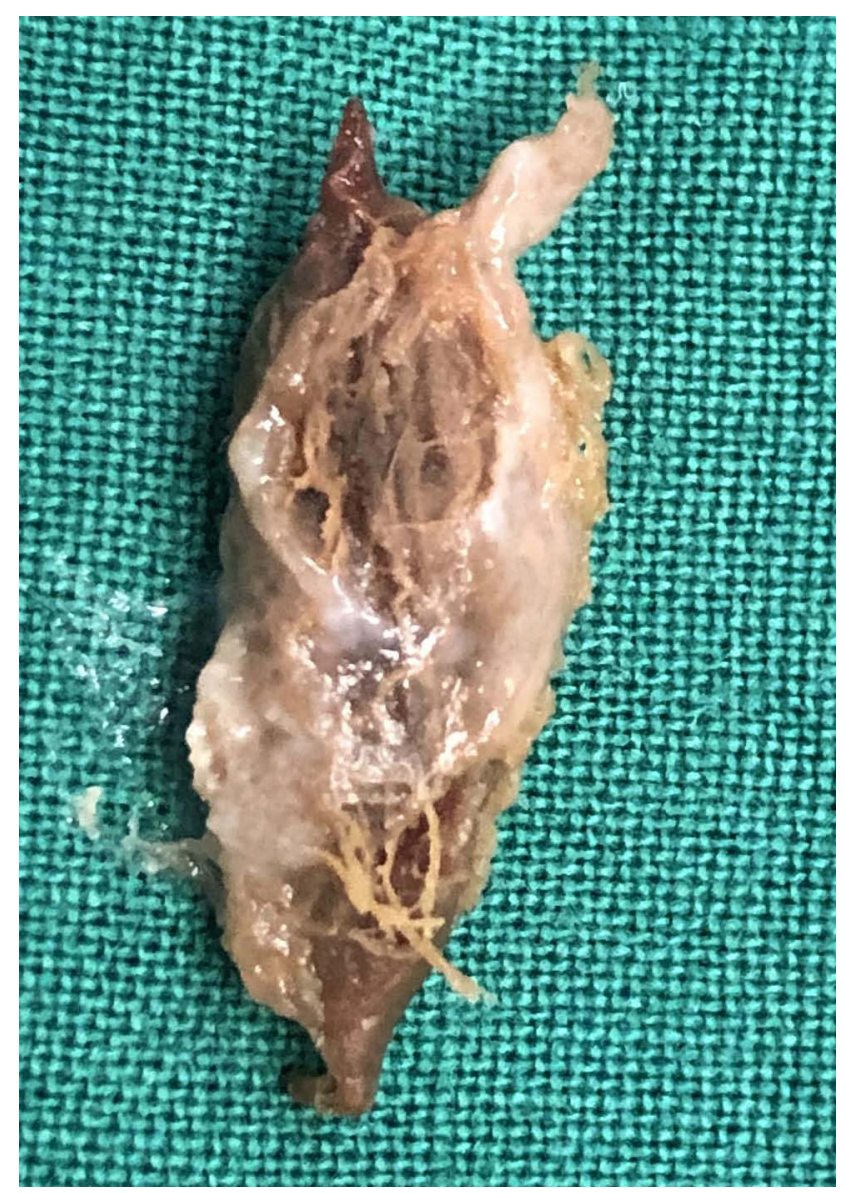

Figure 2 Photograph shows foreign body (jujube pit) removed from patient's esophagus.

annually in the USA. ${ }^{1,2}$ The main finding in our retrospective study was a significant increase in the occurrence of acute EFB ingestion that required surgical extraction under general anesthesia on weekends and holidays compared with weekdays. Patients who underwent EFB extraction on holidays and weekends tended to be much older than those who underwent EFB extraction on weekdays. To the author's knowledge, based on the literature, this is the largest study comparing the occurrence of EFBs during different time periods.

Multifaceted etiologies contributed to esophageal obstruction cased by foreign bodies. Seasonal variation was assessed in a former study, and the highest incidence of acute esophageal obstruction extraction was observed during the summer and fall, which may be due to coexisting atopic diathesis. ${ }^{11}$ Dietary indiscretions, such as excess alcohol ingestion or overeating, could contribute to a higher incidence of EFBs during national athletic events. ${ }^{12}$ Over a 3 -year period, we found that patients were more likely to experience emergency esophageal

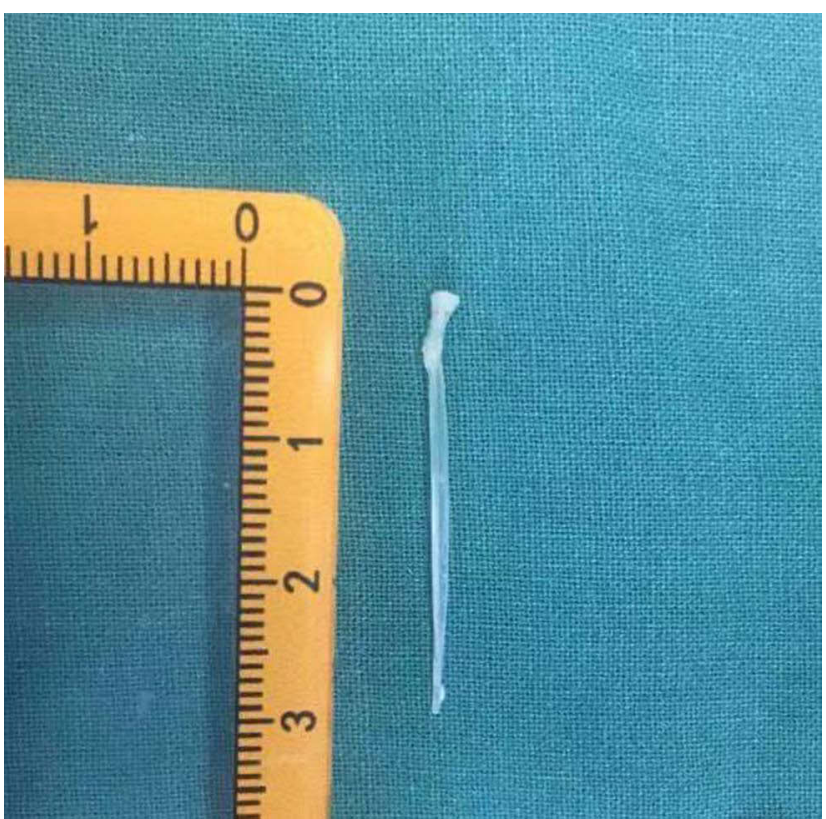

Figure 3 Photograph shows foreign body (fish bone) removed from patient's esophagus.

foreign body extraction on holidays and weekends than on weekdays. On holidays and weekends, people may consume a large meal since eating is a common form of celebration in traditional Chinese cultural. The relatively high occurrence of EFB extraction on holidays, especially among elderly patients (above 55 years), are noteworthy results; these factors may be associated with worse outcomes than those on weekdays. Moreover, studies have demonstrated substandard outcomes for emergent operative indications during the weekend, known as the weekend effect, due to inferior operative performance and perioperative care. ${ }^{13}$

Most ingested foreign bodies can pass through the esophagus and gastrointestinal tract without harm, and foreign bodies lodged in the oropharynx and hypopharynx can be removed in the emergency room. Only a very small minority of patients require surgical treatment in the operation room under general anesthesia which might be associated with increased morbidity and even mortality. ${ }^{6,8,14}$ Current treatment strategies for EFB ingestion seem to vary widely among different hospitals and even among different treatment teams within the same hospital. Surgical intervention with either flexible or rigid esophagoscopy, which has been demonstrated to be equally effective for foreign body removal with no significant differences in overall complications, ${ }^{15,16}$ should be the first-line treatment among patients at a high risk of 
Table I Characteristics and Outcomes of Patients in Weekdays, Weekends and Holidays

\begin{tabular}{|c|c|c|c|c|}
\hline & Weekday & Weekend & Holiday & $\mathbf{P *}$ \\
\hline Days & $58 \mathrm{I}(54.55 \%)$ & $393(36.91 \%)$ & $91(8.54 \%)$ & \\
\hline EFB (no.) & $530(39.17 \%)$ & $573(42.35 \%)$ & $250(18.48 \%)$ & \\
\hline Occurrence (cases/day) & 0.91 & 1.46 & 2.75 & $<0.001$ \\
\hline Female & $326(61.51 \%)$ & $359(62.65 \%)$ & $172(68.8 \%)$ & 0.135 \\
\hline Age, years & $54.7| \pm 16.7|$ & $55.05 \pm 17.36$ & $58.18 \pm 17.34$ & 0.021 \\
\hline \multicolumn{5}{|l|}{ Age $>55$} \\
\hline Occurrence (cases/day) & 0.42 & 0.75 & 1.75 & $<0.001$ \\
\hline Age, years & $67.20 \pm 9.53$ & $68.69 \pm 9.74$ & $69.56 \pm 9.27$ & 0.334 \\
\hline Type of EFBs & & & & 0.537 \\
\hline Fish bone & 164 (30.94\%) & $173(30.19 \%)$ & $76(30.4 \%)$ & \\
\hline Jujube pit & $234(44.15 \%)$ & $248(43.28 \%)$ & $106(42.4 \%)$ & \\
\hline Chicken and duck bone & 78 (14.72\%) & $102(17.8 \%)$ & 49 (19.6\%) & \\
\hline Denture & $20(3.77 \%)$ & 12 (2.09\%) & 9 (3.6\%) & \\
\hline Plastic or metallic item & $15(2.83 \%)$ & $16(2.79 \%)$ & $2(0.8 \%)$ & \\
\hline Shellfish or crab shell & 5 (0.94\%) & $10(1.74 \%)$ & $3(1.2 \%)$ & \\
\hline Food impaction & 14 (2.64\%) & 12 (2.09\%) & $5(2.0 \%)$ & \\
\hline Type of EFBs & & & & 0.537 \\
\hline Fish bone & 164 (30.94\%) & $173(30.19 \%)$ & 76 (30.4\%) & \\
\hline Jujube pit & $234(44.15 \%)$ & $248(43.28 \%)$ & $106(42.4 \%)$ & \\
\hline Chicken and duck bone & 78 (14.72\%) & $102(17.8 \%)$ & 49 (19.6\%) & \\
\hline Denture & $20(3.77 \%)$ & $12(2.09 \%)$ & $9(3.6 \%)$ & \\
\hline Plastic or metallic item & $15(2.83 \%)$ & $16(2.79 \%)$ & $2(0.8 \%)$ & \\
\hline Shellfish or crab shell & 5 (0.94\%) & $10(1.74 \%)$ & $3(1.2 \%)$ & \\
\hline Food impaction & 14 (2.64\%) & $12(2.09 \%)$ & $5(2.0 \%)$ & \\
\hline Location of EFBs & & & & 0.465 \\
\hline The first stenosis & 115 (21.69\%) & 127 (22.16\%) & $6 \mathrm{I}(24.4 \%)$ & \\
\hline The second stenosis & $9(1.69 \%)$ & 12 (2.09\%) & $3(1.2 \%)$ & \\
\hline Upper esophagus & $390(73.58 \%)$ & $419(73.12 \%)$ & $180(72.0 \%)$ & \\
\hline Mid esophagus & $16(3.01 \%)$ & 15 (2.62\%) & $6(2.4 \%)$ & \\
\hline \multicolumn{5}{|l|}{ Complications } \\
\hline Perforation & $80(14.54 \%)$ & $84(14.60 \%)$ & $42(16.8 \%)$ & 0.804 \\
\hline Infection & $13(2.86 \%)$ & $15(2.74 \%)$ & $4(1.47 \%)$ & 0.515 \\
\hline
\end{tabular}

Notes: Values for categorical variables are shown as frequency (percentage) and for continuous variables as mean \pm standard error. *Student $t$ test, Fisher exact test, and Pearson $x^{2}$ test were used as appropriate.

Abbreviation: EFB, esophageal foreign body. 


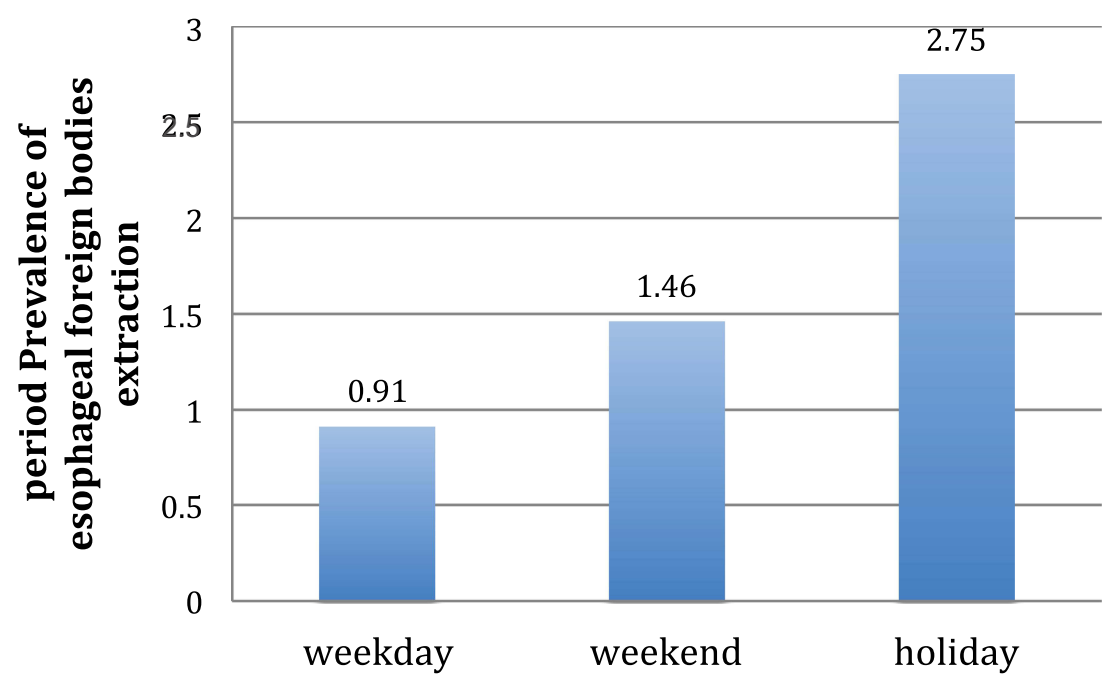

Figure 4 Period prevalence of esophageal foreign body extraction during the weekday, weekend and holiday periods among all people. $\mathrm{P}<0.00 \mathrm{I}$ among three periods. $\mathrm{P}<$ 0.001 among three periods.

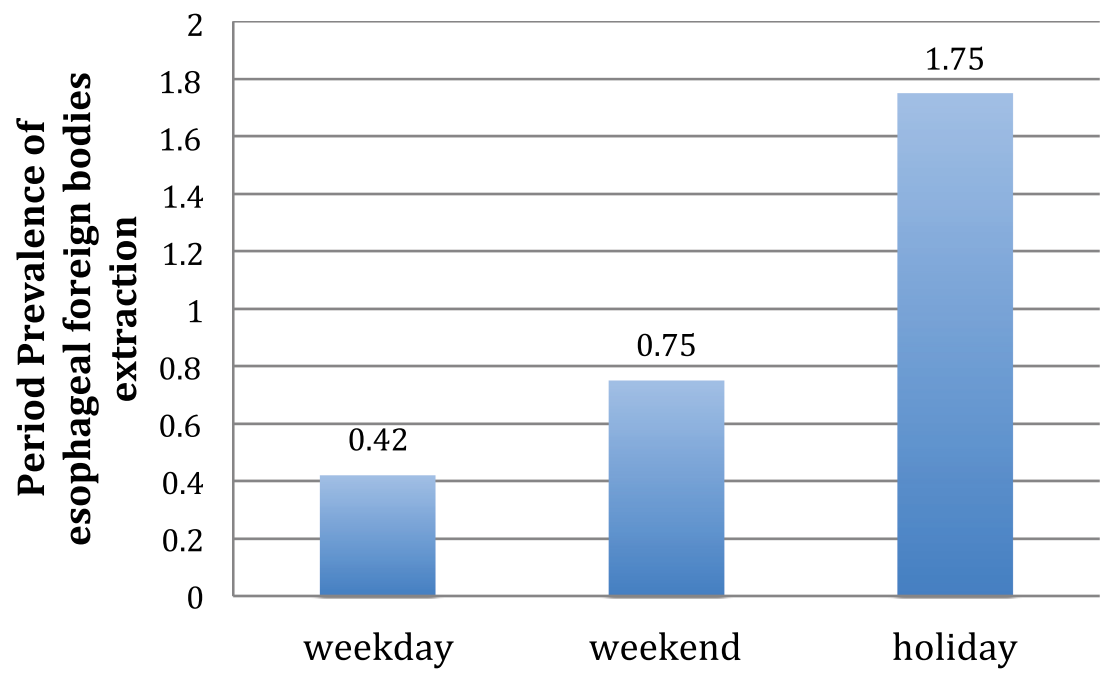

Figure 5 Period prevalence of esophageal foreign body extraction during the weekday, weekend and holiday periods among people above 55 years. $\mathrm{P}<0.00 \mathrm{I}$ among three periods.

morbidity. ${ }^{5,17}$ In contrast to Qian's study, in which all patients underwent foreign body extraction with gastrointestinal endoscope, ${ }^{18}$ patients in a poor condition were generally referred in our center, which is a national tertiary care center that specializes in otolaryngology and received rigid esophagoscopy.

Previous studies have shown a predominance of sharp-pointed objects in adults. ${ }^{6,8,17}$ Our findings are consistent with these results; jujube pits and fish bones accounted for more than two-thirds of all EFBs in this series. The types of foreign bodies may vary according to dietary habits, cultural characteristics, and social cultural factors in different regions and countries. Meat was reported as the most commonly involved food items in the Western Hemisphere, ${ }^{19}$ while fish bones comprised the majority of foreign bodies in South China. ${ }^{20}$ In the present study, jujube pits ranked first, possibly because of the abundance of jujube in northern China. Population aging is a healthcare challenge worldwide, and there is an increasing tendency of dental prosthesis usage, estimated to range from 13 to $29 \%$, in both developed Europe countries $^{21}$ and developing countries. ${ }^{22,23}$ In patients with dental prostheses who underwent EFB extraction under general anesthesia, the burden associated with morbidity and mortality was much greater than that in younger patients. ${ }^{23}$ 
In accordance with previous reports, ${ }^{8,24}$ most of the EFBs in our series were detected in the upper esophageal tract, which includes the narrowest part of the esophagus. The location, type, size, and sharpness of EFBs are considered risk factors for perforation, the most serious complication, potentially causing life-threatening issues such as severe mediastinitis and hemorrhage. ${ }^{7,25}$ In our study, the overall incidence of perforation was $15.23 \%$ (206 patients) over a relatively short time period of 3 years, which was much higher than those in the majority of studies. The reason for this may be that only adults patients were analyzed, and those patients seeking medical care at our center tend to have a serious condition. Although no significant difference was detected among the three groups, the proportion of perforations on holidays was larger than those on weekends and weekdays, which may because that patients on holidays were older and at high risk for complications.

Emergency extraction is usually performed for therapeutic purpose, nevertheless, esophageal obstruction cased by a foreign body can be a warning sign in patients with underlying esophageal disease. ${ }^{26}$ A study analyzed 13,092 patients in 61 studies and found that $25.7 \%$ of patients presenting with EFB ingestion had an underlying esophageal disorder. ${ }^{8}$ Zhang et $\mathrm{al}^{27}$ also determined that $54 \%$ of patients presenting with EFB ingestion had an underlying esophageal disease.

According to our study, public education about chewing slowly and eating non-nuclear jujube should be targeted at elderly individuals to prevent esophageal obstruction. Additionally, medical workers should be fully prepared, especially during holidays and weekends, since more patients at high risk with EFB ingestion are expected to seek treatment.

Our study has several limitations. First, this was a single-center retrospective study, selection bias and referral bias were inevitable, which limit the generalizability of the findings. Prospective, multi-center observational studies based on large population are needed to further validate the result. Second, we focused on only short-term outcomes. Further studies should assess the long-term effects among different periods.

\section{Conclusion}

In conclusion, we demonstrated a significant increase in the occurrence of EFB ingestion on holidays and weekends. Elderly patients should be advised to chewing slowly and eating non-nuclear jujube, especially during holidays, to minimize their risk.

\section{Acknowledgments}

We thank Shaofei Su (Central Laboratory Beijing Obstetrics and Gynecology Hospital, Capital Medical University) for his statistical assistance.

\section{Funding}

This study was supported by Beijing Hospitals Authority Clinical Medicine Development of Special Funding Support (No. ZYLX202103).

\section{Disclosure}

We declare that we have no financial and personal relationships with other people or organizations that can inappropriately influence our work, there is no professional or other personal interest of any nature or kind in any product, service and/or company that could be construed as influencing the position presented in, or the review of, the manuscript entitled "Retrospective analysis of esophageal foreign body ingestion: differences among weekday, weekends, and holidays". The authors report no conflicts of interest in this work.

\section{References}

1. Lyons MF, Tsuchida AM. Foreign bodies of the gastrointestinal tract. Med Clin North Am. 1993;77:1101-1114. doi:10.1016/S00257125(16)30212-7

2. Longstreth GF, Longstreth JF, Yao JF. Esophageal food impaction: epidemiology and therapy. A retrospective, observational study. Gastrointest Endosc. 2001;53:193-198. doi:10.1067/ mge.2001.112709

3. Sugawa C, Ono H, Taleb M, et al. Endoscopic management of foreign bodies in the upper gastrointestinal tract: a review. World J Gastrointest Endosc. 2014;6:475-481. doi:10.4253/wjge.v6.i10.475

4. Eisen TH, Baron TH, Dominitz JA. Guideline for the management of ingested foreign bodies. Gastrointest Endosc. 2002;55:802-806. doi:10.1016/S0016-5107(02)70407-0

5. Lin AY, Tillman BN, Thatcher AL, et al. Comparison of Outcomes in Medical Therapy vs Surgical Intervention of Esophageal ForeignBodies. OtolaryngolHeadNeckSurg. 2018;159:656-661.

6. Long B, Koyfman A, Gottlieb M. Esophageal Foreign Bodies and Obstruction in the Emergency Department Setting: an Evidence-Based Review. $J$ Emerg Med. 2019;56(5):499-511. doi:10.1016/j.jemermed.2019.01.025

7. Birk M, Bauerfeind P, Deprez PH, et al. Removal of foreign bodies in the upper gastrointestinal tract in adults: European Society of Gastrointestinal Endoscopy (ESGE) Clinical Guideline. Endoscopy. 2016;48:489-496. doi:10.1055/s-0042-100456

8. Aiolfi A, Ferrari D, Riva CG, et al. foreign bodies in adults: systematic review of the literature. Scand $J$ Gastroenterol. 2018;53:1171-1178. doi:10.1080/00365521.2018.1526317

9. Kapel RC, Miller C, Torres C, Aksoy S, Lash R, Katzka DA Eosinophilic esophagitis: a prevalent disease in the United States that affects all age groups. Gastroenterology. 2008;134:1316-1321. doi:10.1053/j.gastro.2008.02.016

10. Byrne KR, Panagiotakis K. Retrospective analysis of esophageal food impaction: differences in etiologybyageandgender. DigDisSci.2007. 2014;52:717-721. 
11. Larsson H, Bergquist M, Bove M. The incidence of esophageal bolus impaction: is there a seasonal variation? Otolaryngol Head Neck Surg. 2011;144(2):186-190. doi:10.1177/0194599810392655

12. Shuja A, Winston DM, Rahman AU, et al. food impaction during cultural holidays and national athletic events. Gastroenterolrep $(O x f)$. 2017;5:43-46.

13. Zapf MA, Kothari AN, Markossian T, et al. The "weekend effect" in urgent general operative procedures. Surgery. 2015;158:508-514. doi:10.1016/j.surg.2015.02.024

14. Ferrari D, Siboni S, Riva CG, et al. foreign bodies: observational cohort study and factors associated with recurrent impaction. Eur J Gastroenterol Hepatol. 2020;32:827-831. doi:10.1097/ MEG.0000000000001717

15. Ferrari D, Aiolfi A, Bonitta G, et al. versus rigid endoscopy in the management of esophageal foreign body impaction: systematic review and meta-analysis. World J Emerg Surg. 2018;13:42. doi:10.1186/s13017-018-0203-4

16. Tseng CC, Hsiao TY. Comparison of rigid and flexible endoscopy for removing esophageal foreign bodies in an emergency. J Formos Med Assoc. 2016;115:639-644. doi:10.1016/j.jfma.2015.05.016

17. Nadir A, Sahin E, Nadir I, et al. Esophageal foreign bodies: 177 cases. Dis Esophagus. 2011;24:6-9. doi:10.1111/j.14422050.2010.01085.x

18. Zhong Q, Jiang R, Zheng X, et al. Esophageal foreign body ingestion in adults on weekdays and holidays: a retrospective study of 1058 patients. Medicine(Baltimore). 2015;96:e8409.

19. Longstreth GF, Longstreth KJ, Yao JF. Esophageal food impaction: epidemiology and therapy. A retrospective, observational study. Gastrointest Endosc. 2001;53(2):193-198.
20. Zhang S, Cui X, Gong X, Gu F, Chen M, Zhong B. Endoscopic management of foreign bodies in the upper gastrointestinal tract in South China: a retrospective study of 561 cases. Dig Dis Sci. 2010;55:1305-1312. doi:10.1007/s10620-009-0900-7

21. Zitzmann NU, Hagmann R, Weiger R. What is the prevalence of various types of prosthetic dental restorations in Europe? Clin Oral Implants Res. 2007;18:20-33. doi:10.1111/j.1600-0501.2007.01435.x

22. Orji FT, Akpeh JO, Okolugbo NE. Management of esophageal foreign bodies: experience in a developing country. World J Surg. 2012;36(5):1083-1088. doi:10.1007/s00268-012-1510-7

23. Biancari F, Gudbjartsson A, Fau T. Treatment of esophageal perforation in octogenarians: a multicenter study. Dis Esophagus. 2014;27:715-718. doi:10.1111/dote. 12148

24. Zhang X, Jiang Y, Fu T, et al. Esophageal foreign bodies in adults with different durations of time from ingestion to effective treatment. J Int Med Res. 2017;45(4):1386-1393. doi:10.1177/ 0300060517706827

25. Ikenberry TL, Jue TL, Anderson MA. Management of ingested foreign bodies and food impactions. Gastrointest Endosc. 2011;73 (6):1085-1091. doi:10.1016/j.gie.2010.11.010

26. Straumann A, Bussmann M. Eosinophilic esophagitis: analysis of food impactin and perforation in 251 adolescent and adult patients. ClinGastroenterol Hepatol. 2008;6:598-600.

27. Zhang S, Wen J, Du M, et al. Diabetes is an independent risk factor for delayed perforation after foreign bodies impacted in esophagus in adults. United European Gastroenterol J. 2018;6:1136-1143. doi:10.1177/2050640618784344
Risk Management and Healthcare Policy

\section{Publish your work in this journal}

Risk Management and Healthcare Policy is an international, peerreviewed, open access journal focusing on all aspects of public health, policy, and preventative measures to promote good health and improve morbidity and mortality in the population. The journal welcomes submitted papers covering original research, basic science, clinical \& epidemiological studies, reviews and evaluations,

\section{Dovepress}

guidelines, expert opinion and commentary, case reports and extended reports. The manuscript management system is completely online and includes a very quick and fair peer-review system, which is all easy to use. Visit http://www.dovepress.com/testimonials.php to read real quotes from published authors. 